\title{
From using heat to using work: reconceptualising the zero carbon energy transition
}

\author{
Nick Eyre
}

Received: 23 February 2021 / Accepted: 14 July 2021 / Published online: 27 September 2021

(C) The Author(s) 2021

\begin{abstract}
Recent evidence indicates that the key sources of energy for the zero carbon transition will be renewable electricity sources. The most rapidly expanding sources, photovoltaics and wind produce work, as electricity, directly rather than via heat engines. Making the assumption that these will be the dominant sources of energy in a future zero carbon system, the paper makes two new related and innovative contributions to the literature on the energy transition. First, it shows that the energy transition will be more than just a shift away from carbonaceous fuels, and that it is more usefully thought of as including a systemic shift from heat-producing to work-producing energy sources. Secondly, it shows that this enables very large improvements in the conversion efficiency of final energy, through the use of electricity and hydrogen, in particular in heating and transportation. The paper presents a thought experiment showing a reduction in final energy demand of up to $40 \%$ is likely from this effect alone. Technical standards and product regulation for end use conversion efficiency and/or service delivery efficiency seem likely to be key policy instruments.
\end{abstract}

\section{N. Eyre $(\bowtie)$}

Environmental Change Institute, University of Oxford,

Oxford University Centre for the Environment, South

Parks Road, Oxford OX1 3QY, UK

e-mail: nick.eyre@ouce.ox.ac.uk
Keywords Energy transition - Thermodynamics · Energy efficiency $\cdot$ Final energy

\section{Introduction}

The goals set out in the Paris Agreement almost certainly require the global energy system to move to close to zero emissions, as other emission sources may be harder to abate (Masson-Delmotte et al., 2018). This transition is normally thought of as a shift from carbon-based fuels to zero carbon fuels. This is understandable, but not an adequate approach to understanding a systemic transition. Not only will primary energy sources change, so also will the ways that they are converted and used. In particular, the direct use of fossil fuels in buildings, transport and industry will need to end, and this has significant implications for the types of final energy used and the efficiency of both upstream and downstream conversion processes.

There is an increasing consensus that the lowest cost sources of zero carbon energy will be renewable electricity sources (RES), and that bioenergy, solar photovoltaics (PV), wind energy and hydroelectricity are likely to be particularly important (Grübler et al., 2018; Gielen et al., 2019). With the exception of biomass, these generate electricity directly rather than via combustion and heat engines. Hydropower has been an important source of electricity in favourable geographies for over a century and provides $16 \%$ 
of global electricity (IEA, 2020a). The economics of PV and wind have been transformed in less than a decade, with typical generation costs falling by $82 \%$ and 39\% respectively in the decade to 2019 (IRENA, 2020a).

There is therefore increasing evidence that global energy will rely on RES. They will initially substitute for other, largely fossil fuel, electricity generation. However, the later stages of the transition are less straightforward. Electricity currently provides less than $20 \%$ of global final energy (IEA, 2020a), and therefore a zero carbon energy transition will also involve the decarbonisation of other end uses. Most analysis shows that this will require electricity to substitute for fossil fuels in many other end uses, notably in transportation and heating in buildings and industry (IEA, 2018a). The energy transition can therefore not be achieved without fuel switching in the large number of energy end uses that provide the energy services on which modern life depends.

Most analysis of the transition shows that improvements in energy efficiency will play a role in the energy system change by reducing energy demand below 'business as usual' levels (Edenhofer et al., 2014; Masson-Delmotte et al., 2018). Many projections see energy efficiency improvements mitigating but not reversing global energy demand growth. However, detailed analyses show that the global technical potential for efficiency improvement is very large (Cullen \& Allwood, 2010; Cullen et al., 2011). Recent analysis shows that global energy demand could be reduced, even whilst delivering goals for energy access, poverty alleviation and decent living standards (Grübler et al., 2018).

In summary, it is broadly accepted that there is a major role for energy efficiency improvement in the transition, but that the scale of energy demand reduction is disputed. The dominant conceptualisation is that demand reductions will alter the scale of the decarbonisation challenge, and therefore the amount and cost of the zero carbon energy supply system needed.

This paper will argue that this is not a satisfactory conceptualisation. Given the systemic nature of transition, and in particular the need for fundamental changes in the type of energy used in transport and heating, the flows of energy in the global economy need to change substantially. Changes in the fuels used, and the efficiency of their use, are not just an enabler of the transition, but rather a defining characteristic.

The phrase energy efficiency is potentially confusing in that it is used in both physical and economic analyses of energy use. In the latter case, there is a very large literature on the scope for improving economic productivity through the use of higher efficiency technologies and techniques (see e.g. Ayres and Warr, 2010; Kümmel, 2011; Kümmel, 2013; Laitner, 2015). In this sense of energy efficiency, the phrase 'energy productivity' is often used synonymously. This paper does not seek to add to that literature, but focusses on the physical analysis of energy efficiency.

Even within this restricted use, the term 'energy efficiency' is, confusingly, used with respect to
Fig. 1 Conversion steps in the production of energy services from primary energy, highlighting the focus of the paper
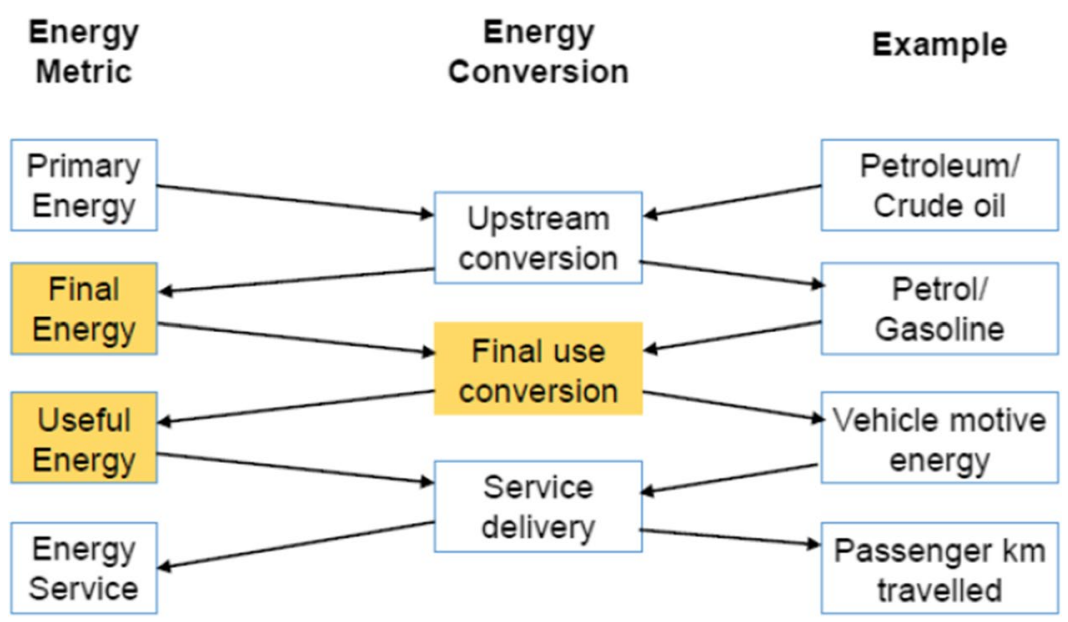
individual processes, sectors and whole systems. Figure 1 sets out the framing and terminology used in this paper. The energy efficiency of the whole system may be improved in three broad ways: firstly, by increasing the efficiency of conversion of primary energy into the final energy delivered to energy users ('upstream conversion efficiency'); secondly, by increasing the efficiency of conversion of that final energy into useful energy at the point of use ('final energy conversion efficiency'); and thirdly, by techniques that allow more energy services to be delivered by the same useful energy ('service delivery'). The latter two categories are often combined in the phrase 'end use efficiency', but are conceptually distinct.

Upstream conversion efficiencies are affected by the transition to RES, in particular through the phasing out of thermal power stations using fossil fuels. However, this paper focusses on the processes highlighted in Fig. 1, i.e. the conversion of final energy into useful energy. As the remainder of the paper shows, these efficiencies are also likely to be affected significantly by the energy transition.

The paper does not explicitly address other contributions to end use efficiency improvement (service delivery), for example through material resource efficiency, transport modal shift and building insulation. This is not because these approaches are not important, indeed it is well-established that they, but because their potential is less likely to be affected by the shift to RES.

The paper poses two research questions:

- What are the broad qualitative changes to energy flows in the global economy that will happen as a result of the energy transition? and

- What are the likely quantitative effects of these on final energy conversion efficiencies and, through these effects, on energy demand?

The 'The thermodynamics of the zero carbon energy transition' section analyses the shift in energy flows that will happen as a result of a shift from fuels that provide heat to RES that provide work, showing that this is a critical issue for the overall energy system. The following two sections undertake a thought experiment on the implications of this change for end use conversion efficiencies and therefore for global final energy demand. The 'Quantification methodology' section sets out the methodology for the quantitative assessment, and the 'Quantification results' section the results of the analysis. The 'Discussion' section discusses some implications for the zero carbon energy transition and the 'Conclusions' section provides key conclusions.

\section{The thermodynamics of the zero carbon energy transition}

Most energy analysis uses the concept of the 'energy system'. Whilst precise definitions differ, the critical understanding is that there are complex links between the ways that different energy sources are converted and transported to provide energy services. Although heat and work are conceptually different, they are strongly linked, and therefore a systems approach is helpful. A common tool to illustrate the point is the Sankey diagram (Sankey, 1898), which shows energy flows from energy sources to energy services.

A highly simplified and non-quantitative Sankey diagram of the global energy system is shown in Fig. 2. In this case, rather than showing fuel types or carbon contents, the diagram makes a distinction between heat and work, both for the energy sources and the energy services provided. Fossil fuels, and some other energy sources, tend to provide heat, as does nuclear power and some RES such as biomass and geothermal energy. Other RES tend to provide work. Most notable in this category are hydropower and the 'new renewables', solar photovoltaics and wind, which have experienced dramatic recent cost reductions (IRENA, 2020a, 2020b). Some energy services require heat, most obviously those associated with space heating, water heating, cooking and many industrial processes; many other energy services, notably movement, require work.

The ability to inter-convert between heat and work is characteristic of modern energy systems, and the constraints on these conversions described in the discipline of thermodynamics. In principle, any mix of energy services can be met by any mix of any energy sources, but often only by utilising heat/work conversions. A more detailed and nuanced analysis of the relationships of different energy sources and energy services to work is provided in Appendix 1. 


\section{Heat and Work in the Global Energy System}

$\begin{array}{lllll} & \begin{array}{l}\text { Upstream } \\ \text { Energy Sources }\end{array} & \text { Final fuels } & \text { End use } & \text { conversion } \\ \text { processes } & & \text { processes } & \text { Services }\end{array}$

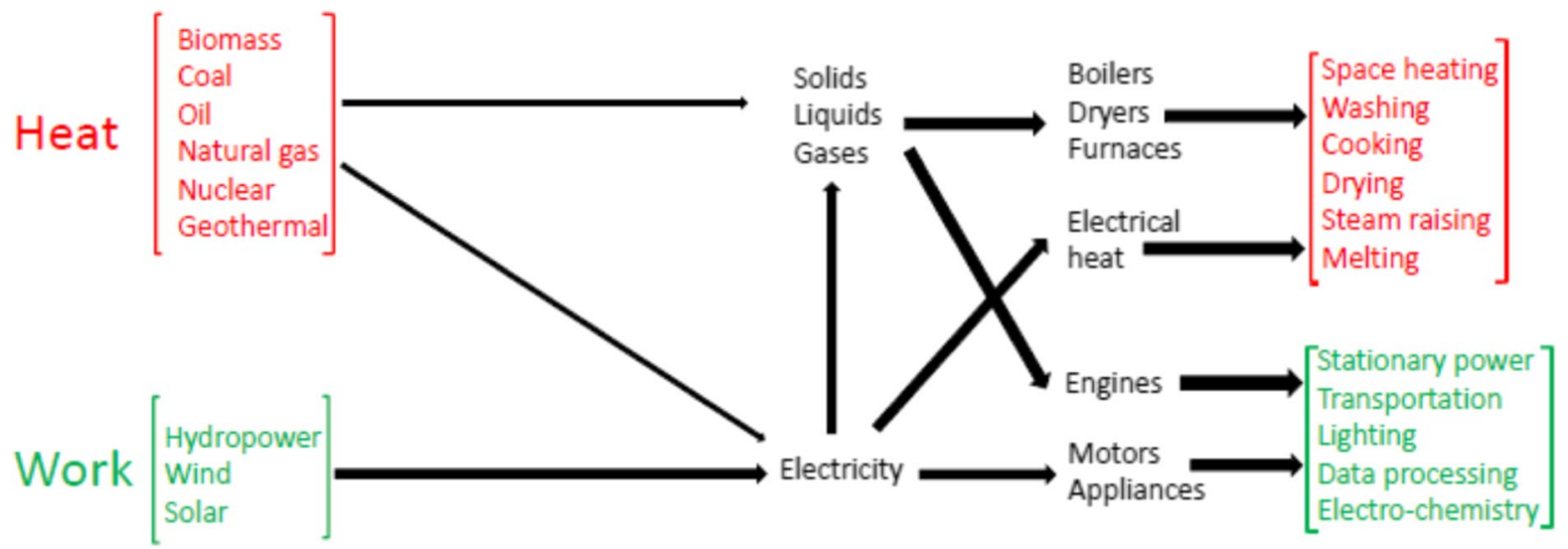

Fig. 2 A stylised Sankey diagram of the energy economy

In pre-industrial societies, the systems of provision for heating services and work were largely separate. Heat was largely produced from wood and was used for cooking, thermal comfort and services requiring hot water, as well as a few other specialised applications such as metal working. Work was provided, largely for motion, from different systems, mostly from the physical labour of humans (hence the name work) or by domesticated animals, with hydropower and wind power in specialised applications, such as milling grain.

The technological changes of the industrial revolution allowed the two systems to connect. This was principally by allowing heat to be converted into work, initially in the late eighteenth century using steam engines, but then from the late nineteenth century by the two dominant technologies of modern energy supply, the internal combustion engine and the turbo-generator. Both provide work from combustible fuels using a heat engine. The former is principally used for decentralised motive power, mainly in transportation. The latter, driven by steam turbines and more recently gas turbines, has become the main source of electricity generation, with electricity then distributed to provide a multiplicity of energy services, including motive power. The science of these conversions has been understood through the discipline of thermodynamics since the mid-nineteenth century.

The combination of internal combustion engines and thermal electricity production has enabled the delivery of modern energy services anywhere on the planet, at least in principle. Energy use has multiplied many-fold and fossil fuels have become the main source of energy. Figure 3 shows a stylised version of such an industrial, fossil fuelled energy system. Fuels are combusted to produce heat as in pre-industrial societies. What the industrial revolution changed fundamentally was that heat was also converted to work to provide transportation, stationary power and other energy services.

The change to low-carbon, and ultimately zero carbon, energy systems seems highly likely to be a transition as fundamental as the changes of the industrial revolution. Current evidence indicates that the cheapest forms of low-carbon electricity will be renewable rather than nuclear and/or fossil fuels with carbon capture and storage (CCS). Already fossil fuels are being displaced from electricity generation by renewables (IRENA, 2020a). Whilst very high levels of variable RES create new challenges for system operators (Jones, 2017), these look soluble, allowing a transition to zero carbon electricity (NGESO, 2020). 


\section{Heat and Work in a Fossil Fuel Energy System}

\begin{tabular}{|c|c|c|c|c|}
\hline Energy Sources & $\begin{array}{l}\text { Upstream } \\
\text { conversion } \\
\text { processes }\end{array}$ & Final fuels & $\begin{array}{l}\text { End use } \\
\text { conversion } \\
\text { processes }\end{array}$ & $\begin{array}{l}\text { Energy } \\
\text { Services }\end{array}$ \\
\hline
\end{tabular}

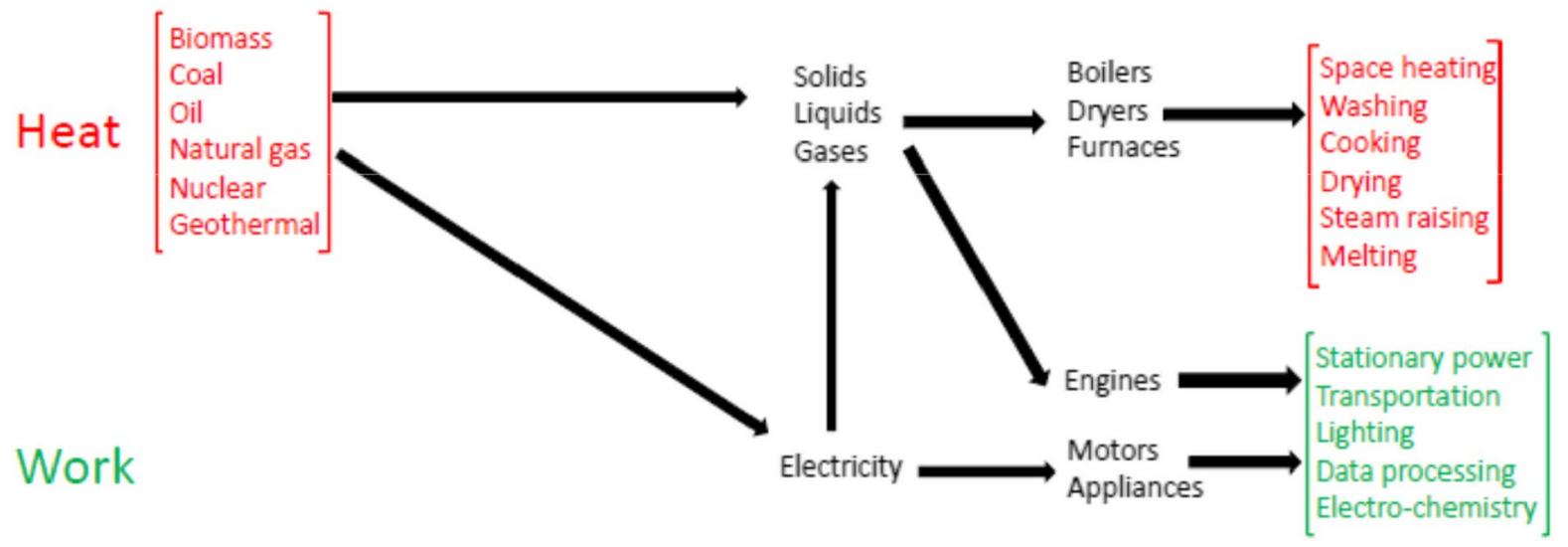

Fig. 3 A stylised Sankey diagram of an industrial economy

A zero carbon energy system will need electricity decarbonisation to be followed by the substitution of fossil fuels elsewhere in the energy system, i.e. for heating, transport and industrial processes. The heatproducing renewables-bioenergy and geothermal energy - may make a contribution. However, most evidence points to this being limited. Use of bioenergy is constrained by land availability, competition for other uses of biomass (notably for food) and relative costs (Smith et al., 2013). The global resource of

\section{Heat and Work in a Renewable Electricity System}

\begin{tabular}{|c|c|c|c|}
\hline Energy Sources & $\begin{array}{l}\text { Upstream } \\
\text { conversion }\end{array}$ & Final fuels & $\begin{array}{l}\text { End use } \\
\text { conversion } \\
\text { processes }\end{array}$ \\
\hline
\end{tabular}

\section{Heat}
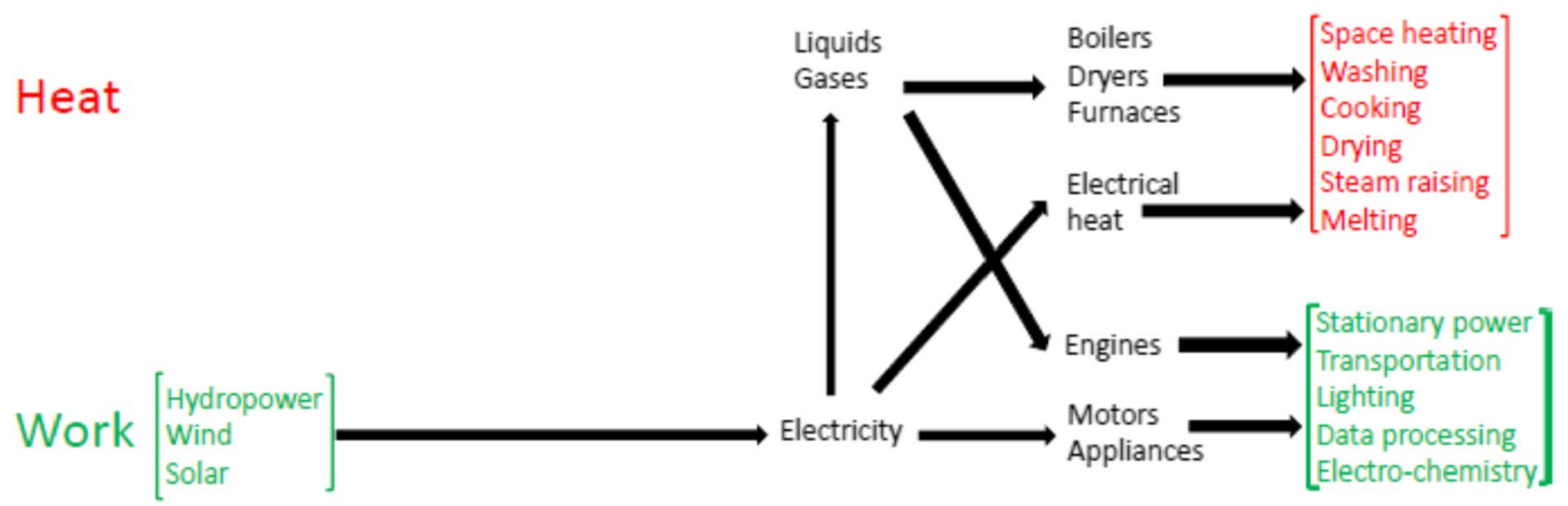

Fig. 4 A stylised Sankey diagram of 100\% renewable economy 
geothermal energy is very large and economic in specific locations, but it is not expected to be competitive in most large, densely populated areas (Goldstein et al., 2011). If this analysis is correct, the main workproducing renewables (solar, wind and hydropower) will need to become the major fuels for transportation and heating, as well as the services currently provided by electricity. The dominant flows of energy in such a 'post-transition' energy system will then be as shown in Fig. 4.

This wider role for electricity in low-carbon economies (Edmonds et al., 2006; Sugiyama, 2012) has become better understood as more ambitious carbon mitigation targets have been established and has been summarised by the IPCC (Edenhofer et al., 2014). The idea that the whole world's energy can be supplied from renewable energy is not new (see e.g. Lazarus, 1993), but only more recent studies of $100 \%$ renewable energy systems (e.g. Lund \& Mathiesen, 2009; Jacobsen et al., 2015; Hansen et al., 2019a; Hansen et al., 2019b) rely heavily on renewable electricity and therefore electrification. Increasingly, it is understood that there are therefore major challenges around the conversion of the $80 \%$ of global final energy use that is not currently electrified. Analyses of sectoral electrification have been undertaken for transport (e.g. McCollum et al., 2014), buildings (e.g. Deason \& Borgeson, 2019) and industry (e.g. Lechtenböhmer et al., 2016). These studies show the potential for increased efficiency through electrification at the level of the individual process and sector.

Some non-academic literature has framed the overall process as a move away from combustion (Lovins, 2013; Patterson, 2014). However, the change is arguably even more fundamental. As shown in Figs. 3 and 4, it is a reversal of the changes that occurred during the industrial revolution. Instead of energy services that require work being provided from fuels via combustion and heat, energy services that require heat will be provided from energy sources that provide work. The whole architecture of energy systems will change, away from converting heat into work, towards converting work into heat.

The scale and rate of change are, of course, likely to vary as a function of resources, investment and politics. However, once the assumption that work-producing renewables will become dominant is accepted, this broad conclusion is unavoidable. Perhaps surprisingly, there is no literature that conceptualises the whole energy transition in this way.
Work-producing RES are already replacing heatproducing fuels, predominantly fossil fuels, in electricity generation. This reduces primary energy demand by eliminating heat losses in thermal power generation. However, it has no direct impact on final energy demand.

With the conceptualisation of a shift from heatproducing to work-producing energy sources, the zero carbon energy transition may be thought of in three subsequent steps, each with implications for the efficiency of final energy conversion, and therefore the scale of final energy demand.

First, without fuels to supply heat engines, end uses of energy requiring work will be converted, where possible, to electricity. The early stages of this step of the transition are already beginning, in particular with electric vehicles substituting for internal combustion engines. As electric motors have a much higher efficiency than heat engines, this change decreases final energy use substantially.

Second, without fuels to produce heat, electricity will also be used for heating. At temperatures below $100{ }^{\circ} \mathrm{C}$, this can also be achieved with a significant reduction in final energy use to supply the same useful energy. This is because electric heat pumps can achieve efficiencies well in excess of $100 \%$ (see Appendix 2 for a discussion of the counter-intuitive idea of efficiencies that exceed 100\%).

Thirdly, it will be necessary to substitute fossil fuels with other options, in cases where electricity use is not a viable alternative. The precise limits to electrification are not agreed, but seem likely to include at least some aviation, shipping, road freight and manufacturing process applications (CCC, 2018a; IEA, 2019). There may also be practical economic limits for the large, seasonally peaked energy service of space heating (Eyre \& Baruah, 2015).

There is a variety of options for alternative carbon-free energy vectors. Hydrogen is the most obvious and most extensively studied (Philibert, 2017). The current dominant production route, using steam reforming of methane, is not carbon neutral, and often referred to as 'grey hydrogen'. It can be converted into a low-carbon vector, 'blue hydrogen', by adding carbon capture and storage to the reformation. Hydrogen can also be produced from water by electrolysis (Brandon \& Kurban, 2017). This 'green hydrogen' is likely to be the major route in an energy system dominated by work-producing RES. 
The electrolytic conversion process can approach $100 \%$ efficiency in theory, but in practice involves an efficiency penalty. However, conversion of hydrogen chemical energy to work using fuel cells enables it to be used more efficiently than fossil fuel in heat engines. The theoretical maximum electrical efficiency of a hydrogen fuel cell (determined by the ratio of the Gibbs free energy to the enthalpy) is $83 \%$ and achievable efficiencies exceed $50 \%$. These are significantly higher than in a heat engine, where the theoretical efficiency is the Carnot limit and materials limit feasible operating temperatures and therefore the efficiency of conversion to work (Lutz et al., 2002). In summary, hydrogen may be used more efficiently than fossil fuels at the point of final energy conversion, because the chemical energy may be converted directly into work rather than heat.

All three stages will tend to increase conversion efficiencies at the point of final energy use, and thereby reduce global final energy demand. The size of the combined effect for the global energy system is investigated in the next two sections. Likely impacts on primary energy use are more complex due to the additional upstream conversion inefficiencies in the third stage and are addressed in the 'Discussion' section.

\section{Quantification methodology}

The principles of the quantification methodology follow from the analysis of the previous section.

For the purposes of this thought experiment, it is assumed that energy is generated entirely from workproducing RES. This is not intended to be a prediction or even a realistic scenario. Even in a $100 \%$ renewables scenario, bioenergy and geothermal may be expected to make a contribution. However, as set out above, it is widely expected that a zero carbon global energy system will be supplied largely by work-producing RES. It is therefore a reasonable first approximation, on which to base an assessment of the impact of the zero carbon transition on the end use conversion technologies needed.

Global energy demand, using a base year of 2020, is estimated from available sources. It is divided into different categories of energy use designed to provide different energy services (e.g. boilers for space heating, high-temperature industrial processes, heavy road freight transport). The extent of disaggregation is determined by the level required to make reasonable allocations into the three categories set out in the previous section, i.e.

- Energy services delivered by work and that can be electrified

- Energy services delivered by heat that can be electrified

- Energy services that cannot practicably be electrified.

Detailed assumptions about current global energy use are set out in Appendix 3. For each category, current global energy use is split into electricity and heat-producing fuels.

The literature on energy efficiency is reviewed to identify existing efficiencies in both electrified and non-electrified cases. Detailed assumptions about conversion efficiencies are set out in Appendix 4. The same process is repeated for the same set of energy services delivered in a zero carbon system, using a mix of electricity and electrolytic hydrogen as the zero carbon vectors to supply final energy demand. The differences in efficiency are applied to current global final energy demand to calculate the size of global demand reduction.

In order to ensure transparency, other efficiency options (e.g. building insulation, vehicle aerodynamics, industrial process control) and energy service demands (e.g. for material resources, thermal comfort or mobility) are held constant. This is not, of course, realistic, as the potential for these to change is very large (Grübler et al., 2018). But this thought experiment approach enables calculation of the effect of supply mix changes on final energy conversion efficiencies without being obscured by these other effects.

\section{Quantification results}

The overall impact of the changes from converting the whole energy system, with a constant level of energy services and useful energy demands, to an efficient work-driven system is approximately a $40 \%$ reduction in final energy demand (see Fig. 5) from 416 to 247 EJ/year. The major efficiency gains are in buildings 
Fig. 5 Changes in global final energy demand due to a shift to using work

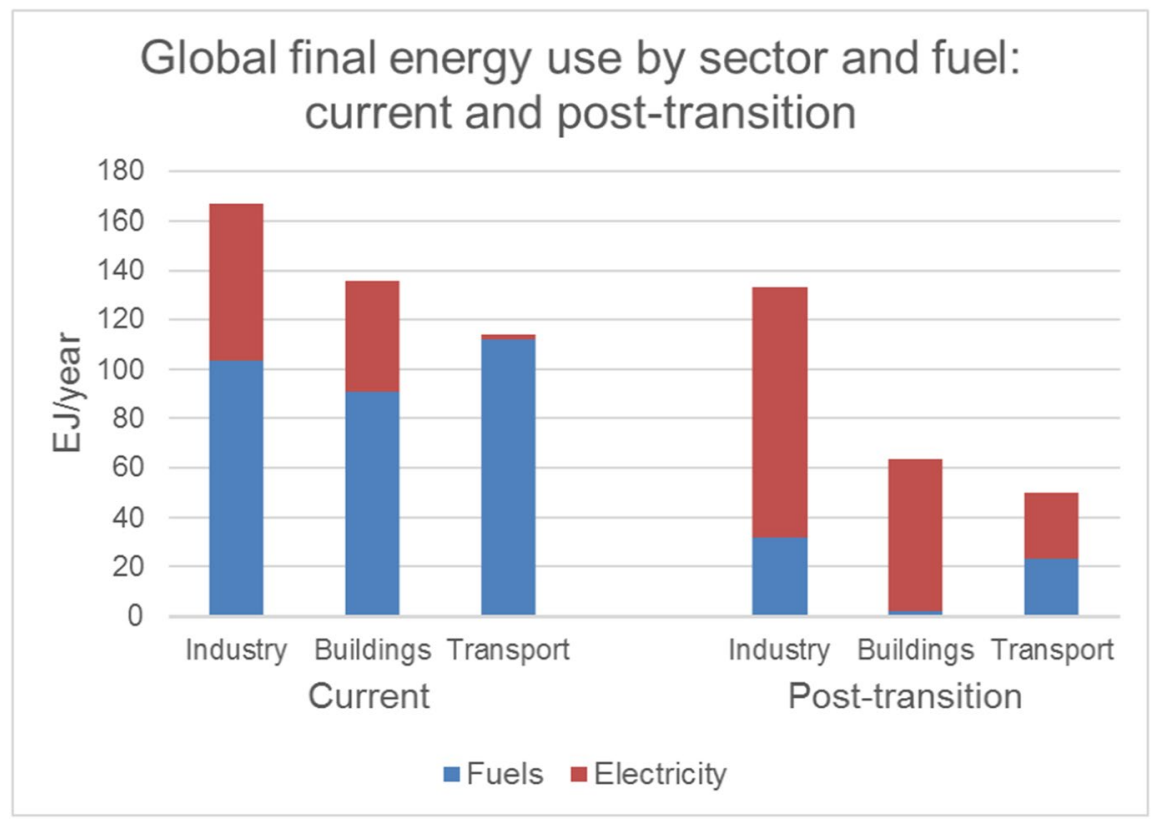

and transport where demand reductions exceed $50 \%$. These are primarily due to converting building heating from fossil-fuelled boilers to electric heat pumps (EHPs) and from switching transport propulsion from internal combustion engines (ICEs) to electric vehicles (EVs). Energy demand reductions in industry are smaller (20\%), as set out in Appendix 4, reflecting the high efficiencies already achieved in energy intensive industry sectors and the difficulties in switching some demands to electricity, especially where fuels play some other role such as a feedstock or chemical reducing agent.

Demands that are not electrified are assumed to be provided by hydrogen. The change in the split between electricity and fuel for each major type of process is shown in Table 1 . The share of electricity use doubles in industry (38\% to $76 \%$ ); almost triples in buildings (33\% to $97 \%$ ) and rises more than 30-fold in transport (less than $2 \%$ to $54 \%$ ). Overall electricity provides $189 \mathrm{EJ}$ (77\%) with hydrogen the remaining $57 \mathrm{EJ}$ (23\%). These compare to the current figures of $110 \mathrm{EJ}$ (26\%) for electricity and $306 \mathrm{EJ}$ (74\%) for other fuels. In other words, fuel use falls to well under $20 \%$ of existing levels, whilst electricity use rises by $70 \%$.

The detailed results are dependent on the precise assumptions set out in the appendices. In particular, the results depend on the assumptions about the energy supply mix and the conversion technologies deployed at the point of energy use.
The major finding that energy services will be delivered much more efficiently in a $100 \%$ work-powered global energy system is robust, provided that EHPs largely replace boilers for low-temperature heating services and EVs largely replace ICE for light vehicles.

In essence, the efficiency gains are a direct result of the fact that the second law of thermodynamics allows greater efficiencies in conversion of work to heat than vice versa. An alternative framing is that 'energy' is a misleading metric, with which to cover both work and heat (and heat at different temperatures). The analytical option of 'exergy analysis' is discussed in Appendix 2. However, the key conclusion of this paper is robust against shifting to exergy analysis. In either framework, the important point is that a unit of work energy will generally provide more useful energy and energy services than a unit of heat energy.

Two major simplifying assumptions made in the thought experiment warrant some consideration: first, that there is no deployment of energy efficiency measures other than the final use conversion efficiency improvements driven by the change to a workbased energy system; and secondly that the demand for energy services is unchanged. Of course, neither of these is a realistic scenario.

Firstly, there remains significant scope for improvement in the energy efficiency with which energy services are produced from useful energy, for example in building insulation and vehicle design. The technical potential for such changes has been estimated to be $73 \%$ 
Table 1 Final energy by process type and fuel: current and post-transition (EJ/year)

\begin{tabular}{|c|c|c|c|c|c|}
\hline & \multicolumn{3}{|c|}{ Current } & \multicolumn{2}{|c|}{ Post-transition } \\
\hline & Fuels & Electricity & $\begin{array}{l}\text { Traditional } \\
\text { biomass }\end{array}$ & Fuels & Electricity \\
\hline \multicolumn{6}{|l|}{ Industry } \\
\hline High-temperature process & 47.2 & 15.9 & & 31.6 & 22.1 \\
\hline Low-temperature process & 24.2 & 6.7 & & 0.0 & 26.1 \\
\hline Drying and separation & 12.0 & 1.7 & & 0.0 & 4.7 \\
\hline Motors, drives and lighting & 0.6 & 31.4 & & 0.0 & 32.0 \\
\hline Space heating & 8.2 & 3.8 & & 0.4 & 3.1 \\
\hline Other & 11.6 & 3.6 & & 0.0 & 12.9 \\
\hline Total industry & 103.8 & 63.1 & & 32.1 & 100.9 \\
\hline \multicolumn{6}{|l|}{ Buildings } \\
\hline Space heating & 38.4 & 2.2 & 3.2 & 2.0 & 10.4 \\
\hline Water heating & 24.1 & 4.3 & 0.0 & 0.0 & 10.7 \\
\hline Cooking & 0.0 & 4.1 & 25.1 & 0.0 & 6.0 \\
\hline Lighting, cooling and appliances & 0.0 & 34.3 & 0.0 & 0.0 & 34.3 \\
\hline Total buildings & 62.5 & 44.8 & 28.3 & 2.0 & 61.4 \\
\hline \multicolumn{6}{|l|}{ Transport } \\
\hline Vans & 14.0 & & & 0.0 & 3.2 \\
\hline $\mathrm{HGV}$ & 15.7 & & & 4.7 & 4.2 \\
\hline Car & 40.2 & & & 0.0 & 9.4 \\
\hline Bus & 13.9 & 0.7 & & 2.1 & 5.8 \\
\hline Motor cycle & 1.5 & 0.2 & & 0.0 & 0.5 \\
\hline Rail freight & 1.6 & 0.5 & & 0.0 & 1.2 \\
\hline Rail passenger & 0.8 & 0.4 & & 0.0 & 0.8 \\
\hline Aviation & 11.1 & & & 5.4 & 1.4 \\
\hline Marine & 13.0 & & & 10.9 & 0.6 \\
\hline Total transport & 111.8 & 1.8 & & 23.1 & 27.0 \\
\hline Total all sectors & 278.1 & 109.8 & 28.3 & 57.2 & 189.3 \\
\hline
\end{tabular}

(Cullen et al., 2011). End use efficiency improvements, in the broadest sense, are therefore not restricted to those shown in Table 1 and Fig. 5. More substantial improvements are possible by combining the conversion efficiency improvements discussed in this paper with other energy efficiency techniques.

Secondly, demand for energy services seems very likely to rise in order to meet rising living standards, especially in the Global South. On the other hand, there are large opportunities for higher-income energy users to reduce consumption of energy services without lower welfare (Ivanova et al., 2020). Combining these effects requires more detailed socio-technical analysis. Doing this for the whole world is complex; the most comprehensive analysis shows that a sustained effort to reduce energy demand whilst enabling all of the UN Sustainable Development Goals to be met can reduce final energy demand by approximately $40 \%$ (Grübler et al., 2018). The similarity of this $40 \%$ reduction number to the conversion efficiency improvement calculated above is a coincidence. The implication is that the projected rise in global energy service demands can be balanced by improvements in the production of energy services from useful energy. The large rises in conversion efficiencies in moving to a work-based energy system then drive the $40 \%$ reduction.

The analysis uses the simplifying assumption that renewable energy is produced as electricity, with direct use of fossil fuels replaced by either electricity or electrolytic hydrogen. To the extent that bioenergy and, perhaps, geothermal heat might contribute to renewable energy supply, this constraint is too limiting. The best uses of limited biomass resources in a low-carbon transition remain disputed (CCC, 2018b) 
and may be very dependent on local resources. Analysis of the issue is outside the scope of this paper, but some production of heat and liquid fuels from bioenergy is likely, and it would be expected to substitute for some of the electrolytic hydrogen projected in the results above. This will tend to increase final energy demand, as biofuels can generally be used less efficiently than hydrogen at the point of final energy use. On the other hand, upstream conversion losses associated with hydrogen production would be reduced. More research is needed on the overall impact of a realistic share of bioenergy on the analysis.

The results imply a growth in use of hydrogen to $57 \mathrm{EJ} / y e a r$. This is four times the existing level of annual global hydrogen production from all sources of 14.4 EJ (IRENA, 2020b). Producing this entirely by electrolysis, assuming an electrolyser efficiency of $80 \%$, which is the median of a major review (Parra et al., 2019), would require $70 \mathrm{EJ} / \mathrm{year}$ of electricity, i.e. over $60 \%$ of total current global electricity production. It would need at least $2500 \mathrm{GW}$ of electrolysis. This vastly exceeds current electrolyser capacity, although it is rising quickly with new investment expected to exceed 1GW/year in 2023 (IEA, 2020b). For the reasons explained above, in practice, use of heat-producing renewables in some applications would be expected to reduce the scale hydrogen demand.

\section{Discussion}

Policy implications

Critical assumptions in the analysis are that EHPs provide most low-temperature heat, EVs predominate in the light vehicle fleet and hydrogen is used primarily in fuel cells in heavy vehicles. These are the high-efficiency options. Based on current analysis, they appear to be the economic options in a zero carbon system. However, it is well-established that a variety of market failures mean that economically optimal technologies are frequently not deployed (Brown \& Wang, 2015; Eyre, 1997). Without policy intervention, some actors in equipment supply industries are likely to market electric resistance technology or hydrogen boilers for low-temperature heating and alternative fuels in ICEs for vehicles. Policy decisions, in particular regulatory standards for heating systems, vehicles and appliances, will continue to be important in ensuring high-efficiency options are used.

In the context of the transition to technologies that use work instead of heat, technical standards and product regulation can be very powerful. The analysis above shows that efficiency standards for heating and vehicles can be approximately a factor of 3 stricter than those currently in place for fossil fuel use. These standards could be set for either or both of the final energy conversion efficiency or the wider service delivery efficiency, e.g. for an electric vehicle, either motor efficiency (\%) or vehicle efficiency $(\mathrm{kWh} / \mathrm{km})$. Setting standards at a level that can only be achieved by well-designed EHPs and EVs effectively will require both the use of final energy that can be used efficiently (electricity or hydrogen) and end use product designs that achieve that efficient use. For this reason, they will be more effective than traditional product policy, which only affects product design. Such standards therefore have the potential to be pivotal in the energy transition.

Interactions between energy service demands and energy efficiency improvements should also be considered. Two may be significant: the impact of embodied energy and economic rebound effects.

Investment in more efficient technologies may increase embodied energy, and therefore industrial energy use. The methodology used in the analysis above treats industrial energy use as independent of the material input for efficiency improvement, and therefore analysing the size of this effect is outside the scope of the paper. It is a significant effect in a few cases, notably for EVs, where manufacturing emissions are currently double those of an ICE vehicle (Wolfram \& Wiedmann, 2017). In principle, these lifecycle considerations could be included within product standards and regulations. However, any such adjustment would be a second-order effect compared to differences between operational energy use in ICEs and EVs.

By treating demand for energy services as fixed, the methodology also neglects any rebound effects from improved energy efficiency. Direct rebound effects are typically 10-30\% (Sorrell, 2007). And historical economy wide effects have been found to be larger (Brockway et al., 2021), which follows from the importance of exergy efficiency in the economy. However, rebound effects specific to the 
improved conversion efficiencies addressed here are unknown. Rebound is driven by energy cost reductions, increased incomes and higher levels of economic productivity, not physical metrics. Many of the conversions envisaged will not lead to significant energy cost reductions, as they involve switching to higher-priced fuels, and therefore historical relationships may not be reproduced. In any event, rebound cannot be addressed by technical standards. To the extent it is judged undesirable, it requires economic disincentives.

Implications for primary energy demand

The analysis above relates to final energy demand, not primary energy. However, it is straightforward to make a preliminary assessment of the effects described above of primary energy demand. International Energy Agency data shows that, in the current global energy system, $70 \%$ of total primary energy supply (TPES) is used for final energy use (IEA, 2020c). The remaining 30\% is lost in various upstream conversion processes. The main loss $(20 \%$ of TPES) is in thermal power generation, with $8 \%$ in other fuel industry processes (largely in coal conversion to coke and oil refining). Losses in electricity transmission and distribution are $1.6 \%$ of TPES (approximately $10 \%$ of electricity generated). In a fully work-based energy system, these numbers will be very different. Losses in thermal power generation and fuel industry processing will be eliminated. As electricity becomes the dominant energy vector, distribution losses would be expected to rise to approximately $10 \%$ of TPES.

The other new source of upstream conversion losses will be in hydrogen production. Assuming an $80 \%$ efficiency in electrolysis, with $23 \%$ of final energy delivered as hydrogen, these conversion losses will be $5 \%$ of TPES. As explained above, these might be reduced if bioenergy replaces some uses of hydrogen. Depending on the resources used to balance electricity systems with high levels of variable resources, there may also be additional losses in upstream electrochemical storage and electricity generation from stored hydrogen. However, total upstream losses seem very likely to be smaller than in the existing global energy system. A $40 \%$ reduction in final energy demand will therefore be reflected in a reduction in primary energy demand of at least $40 \%$.
Timescales of change

The analysis compares the current global energy system with that after a complete transition to work-producing energy sources. The time taken to achieve this is not explicit in the analysis. There is no expectation that different aspects of the transition will have similar timescales. Indeed, it seems very likely that, for example, the adoption of EVs in some developed countries will be more rapid that the complete phase-out of traditional cooking fuels in the Global South. The results are simply a comparison of starting conditions and a projected future end state. However, the overall reconceptualization does have implications for the timescales of the transition. The timescales for different technology transitions are very variable, providing some encouragement that system change by mid-century is plausible (Sovacool, 2016). However, it is clearly also true that large-scale transitions of the type seen in industrial revolutions have tended to be slower (Grübler et al., 2016). The revised conceptualisation set out in this paper shows that the zero carbon transition has the character of an industrial revolution in that it is a complex, multi-stage process, involving multiple technologies, infrastructure systems and many actors. This tends to support arguments that a very rapid complete transition is probably unrealistic.

\section{Conclusions}

The energy transition is normally conceptualised as a shift from fossil fuels to zero carbon energy sources, with the role of energy efficiency limited to reducing the scale of demand for energy, and therefore the amount of decarbonised energy required. This paper has shown that this is a seriously inadequate representation of the changes in energy systems implied by the transition to zero carbon. Recent evidence shows that the key energy sources are likely to be 'work producing' renewables. As these replace 'heat producing' fossil fuels, the changes in the energy system are more profound than simply fuel switching. They constitute a systemic change on the scale of the changes observed during the industrial revolution.

Substitution of fossil fuels by renewables is only the first stage of the transition. To achieve a zero carbon energy system, it needs to be followed by changes that enable 'work producing' renewables to supply energy services not currently supplied by electricity. The dominant energy conversion processes in the global energy system will therefore be 
different. In particular, electricity will be converted to heat and other zero carbon fuels. The transition as a whole cannot adequately be conceptualised as independent processes of shifting to zero carbon fuels and improved energy efficiency. The two have strong positive synergies.

The paper presents a thought experiment on the implications for global final energy conversion efficiency in an energy system in which all energy is supplied by workproducing energy sources. It assumes that all final energy is supplied as either electricity or electrolytic hydrogen, but the broad conclusion is robust to inclusion of some other renewable energy sources. Both electricity and hydrogen can be used more efficiently than the other fuels that dominate final energy use, and this is a very significant effect. Making transparent and plausible assumptions about the end use conversion processes used, the paper finds that there is a very large increase in the overall efficiency of final energy conversion. Total useful energy to deliver the same energy services is reduced by approximately $40 \%$, with the main effects in buildings and transport. Holding other drivers of final energy demand constant, this will have a proportional effect on global final energy demand. A similar impact on primary energy demand is likely.

Technical standards and product regulation for end use conversion efficiency and/or service delivery efficiency seem likely to be key policy instruments. They have the potential both to ensure product designs that use energy efficiently and to drive the transition to final energy sources that enable such use.

\section{Appendix 1 Heat and work from energy sources and in energy services}

Energy services can be divided into two categories: firstly those that are essentially delivered by heating (raising the temperature of something), and secondly those that are delivered by some other form of energy (e.g. electrical or mechanical work).

In buildings, raising the temperature of the building, heating water and the variety of different forms of cooking are all forms of heating services. In industry, there are a large number of processes that depend on heating to a wide range of different temperatures. In contrast, in transport there are few heating-related services. Services in industry and buildings that are traditionally only provided by electricity tend to be workrelated, notably the provision of motive power through electric motors, but also increasingly information services. In transport, the service itself can only be provided by work, but has typically relied more on local conversion of fuels in internal combustion engines.

There are some services which are a little more complex to categorise. Space cooling is, in principle, a heating service, but it predominantly supplied by refrigeration systems driven by electric motors. For the purposes of this analysis, it is therefore classified as a work-related service. Similarly, the heat required for hot water in washing machines and dishwashers is predominantly supplied by electricity. The analysis also treats lighting as a work-related service. The oldest lighting technologies, candles and oil lamps, used combustion, but modern lighting devices require electrical work, either to achieve the high temperatures needed for incandescence in the visible spectrum or in modern devices, such as light-emitting diodes (LED) and fluorescent lamps, to convert electricity selectively into photons in the visible spectrum.

Some industrial processes are also complex to categorise within this simple heat/work binary division. Notably, electrochemical reactions, by definition, require work in the form of electricity, but may also require heat, for example in the Hall-Héroult process for primary aluminium manufacturing. We classify these as work related, due to the essential role of electricity. In some other electricity using processes, notably electric arc steelmaking, electricity is a heat-producing fuel. In other cases, such as petrochemical and ammonia production and primary steel-making, fossil fuels provide a chemical reagent as well as heat. In this paper, they are categorised as requiring heat, and the accounting process set out in Appendix 4 below requires the replacement of fossil fuels by some other combustion fuel.

For the purposes of this paper, we also make a binary division of energy sources into those that provide work and those that provide heat. In the current global energy system, fossil fuels are the dominant producers of heat. Biomass also provides heat via combustion and geothermal energy exists as a heat source. In addition, the energy from nuclear fission, although originating as high energy particles and photons, has only ever been captured as heat. Where these energy sources are required to provide work, this has been done through heat engines of various kinds. In some cases, it has proved an efficient option to use these fuels for combined heat and power (CHP), i.e. to use heat rejected from the heat engine to provide heating services. 
Most other forms of renewables produce only work, usually in the form of mechanical work. These include power from wind turbines, hydro-dams, waves and tidal energy.

Solar energy can be used to provide work or heat. Examples of the latter include 'passive solar gain' for space heating, 'active solar heating' of water and 'concentrating solar power' for electricity generation using heat engines. However, the rapid growth in solar energy has been driven by the use of photovoltaics, which convert solar energy directly into electrical work (the inverse process of LED lighting). For the purposes of this paper, we therefore treat solar energy as a source of work.

\section{Appendix 2 Energy efficiency and its metrics}

The term energy efficiency does not have a universally agreed definition. Like any form of efficiency, it can be conceptualised as the ratio of a 'useful output' to a 'total input', but these terms are not defined or used consistently.

The broadest and commonest definition of 'useful output' is the energy service delivered. This enables incorporation of all the technical and social changes that might be utilised to improve the efficiency of energy service delivery, including for example modal switch in transport, materials utilisation efficiency in industrial production, and insulation of buildings to reduce heat loss or gain. However, energy services are frequently difficult to measure and, in some cases, even to define. For some important energy services, such as thermal comfort and mobility, the appropriate metrics are not specified in terms of energy units, and therefore the metric of the efficiency of their delivery (e.g. passenger km per Joule for mobility) are service specific. This prevents meaningful aggregation across different service categories.

In the context of this paper, the definition of energy efficiency is more straightforward, as the types of efficiency improvement considered are confined explicitly to the efficiency of conversion devices for different forms of final energy use, for example the substitution of boilers by heat pumps and internal combustion engines by electric motors. These devices have better-defined inputs and outputs, both measured in energy units. In essence, the output metric of energy service in broader definition of energy efficiency is replaced with 'useful energy output'. The measure of efficiency is therefore the ratio of useful energy output to final energy input, a dimensionless ratio, normally quoted as a percentage.
There are limits to achievable efficiencies as a result of the second law of thermodynamics. Indeed, the key findings of this paper - that work may generally be converted to heat more efficiently than heat may be converted to work-result largely from that law. In some cases, for example in heat pumps and refrigerators, this enables work to be used at efficiencies of greater than $100 \%$, as the work is used to pump heat, to or from ambient, and the conventional definition of 'energy input' excludes ambient heat and coolth.

So, whilst both heat and work are measured in energy units, they are not generally of equal value. An alternative framing that addresses this inequality is exergy analysis (Moran \& Sciubba, 1994), where exergy is a measure of the ability of an energy source to do work. Exergy therefore has a numerically equal value to that for energy when work is measured, but a smaller numerical value for energy as heat, with the degree of 'down-rating' dependent on temperature. Various authors have preferred exergy analysis when investigating the scope for technology improvement within current energy systems (Hammond \& Stapleton, 2001). In exergy analysis, heat engines, e.g. turbines and internal combustion engines, have theoretical maximum efficiencies of $100 \%$, compared to a much lower value in energy analysis. And the maximum efficiency of a heat pump cannot exceed $100 \%$.

Exergy analysis is well-established in thermodynamics and has a long history ecological economics (GeorgescuRoegen, 1993). However, it is scarcely used in energy economics and policy. Almost all global and national data sources, models and policy analyses are constructed in terms of energy, not exergy. In this paper, we use energy analysis, primarily for that reason. It would be possible to reconstruct the analysis in exergy terms. The numerical values in the results would be different. Energy sourced from heat would have lower relative numerical values than that sourced from work, and the energy services requiring heat would have lower relative numerical values than those requiring work. The shift in the global energy economy described in this paper, from heat-producing energy sources to work-producing energy sources, would appear partly as a change in these relative values, rather than increased conversion efficiencies. But the reality represented would, of course, be the same. The key conclusion of the paper would be still be that the final energy needed to provide the same energy services is lower from a work-based system than a heat-based system. 


\section{Appendix 3 Current global energy use assumptions}

Industry

Assumptions about current energy use in industry are shown in Table 2.

Total industrial energy use is taken from Low Energy Demand scenario for 2020 by Grübler et al. (2018). The split across between different major industrial sectors is taken from Fig. 2 of Cullen and Allwood (2010).

Reliable data for the splits by process type and fuel within each industrial sub-sector are not available at the global level. To estimate these for this paper, we have used UK data (ECUK, 2020) as the default. This implicitly assume that global practice within each sector is similar, which is a reasonable assumption in most cases. Where UK data does not conform to the sectoral split in Table 2, we have made supplementary assumptions as follows. UK data does not distinguish between steel and non-ferrous metals. We assume that the aluminium industry uses $40 \%$ of the electricity and $10 \%$ of the other fuels of the total metals sector, based on Energy Information Administration data (EIA, 2014). Within the steel industry, the fuel split is $79 \%$ fuels and $21 \%$ electricity, based on the work of He and Wang (2017). UK data on paper is aggregated with printing and publishing and therefore not representative of the global paper industry. The paper industry split between drying and separation and other low-temperature process therefore uses data on paper mills and pulp mills from Lawrence et al. (2019).

Petrochemicals account for about $12 \%$ of global oil use (IEA, 2018b), and therefore about $4 \%$ of global primary energy use. In this analysis, it is implicitly assumed that oil used as a feedstock may be substituted in the same way as oil used for energy in the chemical sector. This is a significant simplification, but not a major uncertainty in the context of the whole analysis.

\section{Buildings}

Total energy demand in buildings in 2020 and the shares of fossil fuels, electricity and traditional biomass are taken from the same Low Energy Demand scenario (Grübler et al., 2018). In order to estimate the energy use in different process types, total demand is first split into separate contributions from residential and non-residential, assuming the former is $74.3 \%$

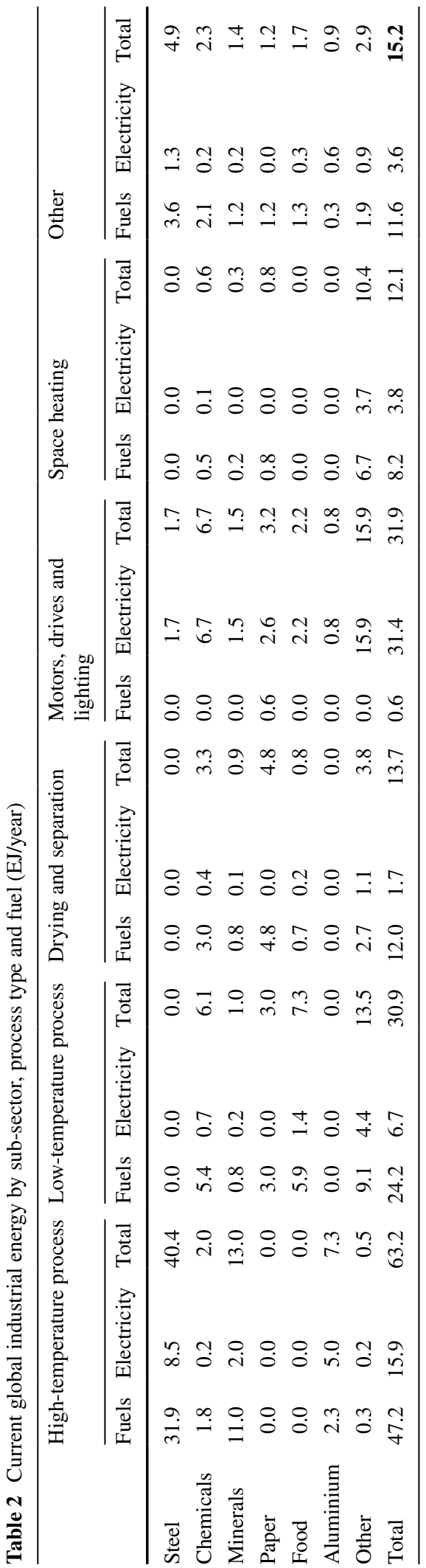


Table 3 End use process split of energy use in buildings

\begin{tabular}{llc}
\hline End use & Residential & Non-residential \\
\hline Space heating & $32.0 \%$ & $33.0 \%$ \\
Water heating & $24.0 \%$ & $12.0 \%$ \\
Cooking & $29.0 \%$ & $0.0 \%$ \\
Lighting & $4.0 \%$ & $16.0 \%$ \\
Cooling & $2.0 \%$ & $7.0 \%$ \\
Appliances/ICT & $9.0 \%$ & $32.0 \%$ \\
\hline
\end{tabular}

(Lucon et al., 2014). These are then each split into the different end use processes using the shares shown in Table 3 (Lucon et al., 2014).

The end use fuel is assumed to be $100 \%$ electricity for lighting, cooling and appliances. Electricity use in cooking is assumed to be $3 \%$ of total building demand, with the remainder of cooking energy use from traditional biomass. The remaining traditional biomass demand is assumed to provide space heating. The shares of electricity for space heating and water heating are assumed to be $5 \%$ and $15 \%$ of the total for each end use. This ensures that the total share of electricity in the sector as a whole corresponds to the overall fuel mix assumed.

\section{Transport}

Data on transport energy use by mode and fuel type are taken from the Supplementary Information of Khalili et al. (2019) and set out in Table 4.

End use demands smaller than 0.1EJ/year have been neglected. End use devices are assumed to be internal combustion engines for fuel and electric motors for electricity. Total energy use is consistent with the same Low Energy Demand scenario (Grübler et al., 2018) as the other sectors.

\section{Appendix 4 Future energy conversion assumptions}

This section sets out the methodology used to calculate future final energy demands. Current energy demands by process type and fuel (see Table 1 and Appendix 3) are the starting point. For simplicity and transparency, it is assumed that there are no changes in energy services demands and no changes to energy efficiency other than in conversion processes from final energy to useful energy.
Table 4 Global transport energy use by fuel and mode (EJ/ year)

\begin{tabular}{lrl}
\hline & Fuel & Electricity \\
\hline Road & & \\
$\quad$ Light goods vehicles & 14.0 & \\
Heavy goods vehicles & 15.7 & \\
Cars & 40.2 & \\
$\quad$ Buses & 13.9 & 0.7 \\
$\quad$ Motor cycle & 1.5 & 0.2 \\
Rail & & \\
$\quad$ Rail freight & 1.6 & 0.5 \\
$\quad$ Rail passenger & 0.8 & 0.4 \\
Aviation & & \\
$\quad$ Aviation freight & 0.1 & \\
$\quad$ Aviation passenger & 11.0 & \\
Marine & & \\
$\quad$ Marine freight & 12.7 & \\
Marine passenger & 0.3 & \\
Total & 111.8 & 1.8 \\
\hline
\end{tabular}

All end uses are supplied by either electricity or hydrogen. Electricity is assumed to be the preferred zero carbon end use fuel in most applications. Hydrogen is used for those demands judged from the existing literature to be difficult to electrify. These include industrial processes, heavy vehicles, shipping and aviation, and some space heating.

Detailed assumptions are set out below in Table 5. This documents the conversion factors used for each combination of sector and process type (e.g. 'industry, high temperature process'). Table 5 is essentially a set of $2 \times 2$ matrices that document the conversion factors used to calculate post-transition energy demands, split into fuel and electricity, from the pre-transition fuel mix. As an example, the quantity of (non-electric) fuels used in industrial high-temperature processes falls to $67 \%$ of its pre-transition level, $13 \%$ of pre-transition direct fossil fuel appears as electricity post-transition and the remaining $20 \%$ is the final energy efficiency gain. For the same set of processes, all the energy currently provided by electricity is unaffected.

'Pre-transition fuels' are predominantly fossil fuels; 'post-transition fuels' are assumed to be hydrogen. For the buildings sector, an additional current fuel type is considered: traditional biomass. But there is no traditional biomass in the final fuel mix, and 
Table 5 Conversion factors between current and future fuel and electricity use

\begin{tabular}{|c|c|c|c|}
\hline Sector and process & Pre-transition energy & Fuel & Electricity \\
\hline \multicolumn{4}{|l|}{ Industry } \\
\hline \multirow[t]{2}{*}{ High-temperature process } & Fuels & $67.0 \%$ & $13.2 \%$ \\
\hline & Electricity & $0.0 \%$ & $100.0 \%$ \\
\hline \multirow[t]{2}{*}{ Low-temperature process } & Fuels & $0.0 \%$ & $80.0 \%$ \\
\hline & Electricity & $0.0 \%$ & $100.0 \%$ \\
\hline \multirow[t]{2}{*}{ Drying and separation } & Fuels & $0.0 \%$ & $33.3 \%$ \\
\hline & Electricity & $0.0 \%$ & $41.7 \%$ \\
\hline \multirow[t]{2}{*}{ Motors, drives, lighting } & Fuels & $0.0 \%$ & $100.0 \%$ \\
\hline & Electricity & $0.0 \%$ & $100.0 \%$ \\
\hline \multirow[t]{2}{*}{ Space heating } & Fuels & $5.3 \%$ & $23.2 \%$ \\
\hline & Electricity & $0.0 \%$ & $32.3 \%$ \\
\hline \multirow[t]{2}{*}{ Other } & Fuels & $0.0 \%$ & $80.0 \%$ \\
\hline & Electricity & $0.0 \%$ & $100.0 \%$ \\
\hline \multicolumn{4}{|l|}{ Buildings } \\
\hline \multirow[t]{3}{*}{ Space heating } & Fuels & $5.3 \%$ & $23.2 \%$ \\
\hline & Electricity & $0.0 \%$ & $32.3 \%$ \\
\hline & Traditional biomass & $0.0 \%$ & $25.8 \%$ \\
\hline \multirow[t]{3}{*}{ Water heating } & Fuels & $0.0 \%$ & $36.4 \%$ \\
\hline & Electricity & $0.0 \%$ & $45.5 \%$ \\
\hline & Traditional biomass & $0.0 \%$ & $36.4 \%$ \\
\hline \multirow[t]{3}{*}{ Cooking } & Fuels & $0.0 \%$ & $62.5 \%$ \\
\hline & Electricity & $0.0 \%$ & $100.0 \%$ \\
\hline & Traditional biomass & $0.0 \%$ & $7.5 \%$ \\
\hline \multirow[t]{3}{*}{ Lighting, cooling and appliances } & Fuels & $0.0 \%$ & $100.0 \%$ \\
\hline & Electricity & $0.0 \%$ & $100.0 \%$ \\
\hline & Traditional biomass & $0.0 \%$ & $100.0 \%$ \\
\hline \multicolumn{4}{|l|}{ Transport } \\
\hline \multirow[t]{2}{*}{ Vans } & Fuels & $0.0 \%$ & $23.3 \%$ \\
\hline & Electricity & $0.0 \%$ & $100.0 \%$ \\
\hline \multirow[t]{2}{*}{ Heavy goods vehicles } & Fuels & $30.1 \%$ & $26.6 \%$ \\
\hline & Electricity & $0.0 \%$ & $100.0 \%$ \\
\hline \multirow[t]{2}{*}{ Cars } & Fuels & $0.0 \%$ & $23.3 \%$ \\
\hline & Electricity & $0.0 \%$ & $100.0 \%$ \\
\hline \multirow[t]{2}{*}{ Bus } & Fuels & $15.3 \%$ & $36.6 \%$ \\
\hline & Electricity & $0.0 \%$ & $100.0 \%$ \\
\hline \multirow[t]{2}{*}{ Motor cycles } & Fuels & $0.0 \%$ & $23.3 \%$ \\
\hline & Electricity & $0.0 \%$ & $100.0 \%$ \\
\hline \multirow[t]{2}{*}{ Rail freight } & Fuels & $0.0 \%$ & $40.0 \%$ \\
\hline & Electricity & $0.0 \%$ & $100.0 \%$ \\
\hline \multirow[t]{2}{*}{ Rail passenger } & Fuels & $0.0 \%$ & $45.0 \%$ \\
\hline & Electricity & $0.0 \%$ & $100.0 \%$ \\
\hline \multirow[t]{2}{*}{ Aviation } & Fuels & $48.4 \%$ & $12.4 \%$ \\
\hline & Electricity & $0.0 \%$ & $100.0 \%$ \\
\hline \multirow[t]{2}{*}{ Marine } & Fuels & $83.6 \%$ & $4.5 \%$ \\
\hline & Electricity & $0.0 \%$ & $100.0 \%$ \\
\hline
\end{tabular}


therefore the conversion matrices are $3 \times 2$ for this sector.

In industry, it is assumed that changes in hightemperature process conversion efficiency are dominated by those in the steel sector. Currently electric arc furnaces produce only $25 \%$ of steel globally, but this is very variable across countries ranging from $50 \%$ in most OECD countries to only $10 \%$ in China (He \& Wang, 2017). Electric arc furnaces use only $40 \%$ of the final energy of the blast furnace process route. We assume that the global industry shifts to the current process mix of the OECD. Production of iron by hydrogen direct reduction has a similar energy consumption to blast furnace production (Vogl et al., 2018).

Low-temperature processes in industry are very largely dependent on steam. Process change as a direct outcome of the energy transition is therefore unlikely (although the changing costs of different fuels may lead to innovation). The change envisaged here is therefore a shift from fossil fuel to electric boilers with a $20 \%$ conversion efficiency improvement.

Drying and separation processes at temperature below $120{ }^{\circ} \mathrm{C}$ are amenable to conversion to heat pumps using existing technology. It is assumed that $80 \%$ efficient boilers and $100 \%$ efficient electrical technologies are replaced with heat pumps with a coefficient of performance of $240 \%$ (Arpagaus et al., 2018).

It is assumed that space heating changes are achieved consistent with those in the buildings sector set out below. Changes in other end uses are assumed to reflect those in low-temperature process to ensure a conservative assessment of potential.

In buildings, space heating is the largest energy user in cool and temperate climates. From an efficiency perspective, the ideal solution is to use highefficiency heat pumps. However, there are concerns that $100 \%$ substitution may not be economic due to the very large peak in winter electricity demand it could cause (Eyre \& Baruah, 2015). We therefore assume that some hydrogen contribution will be needed. We assume that existing fuels are replaced by $90 \%$ electricity and $10 \%$ hydrogen. We assume a long term achievable efficiency of $310 \%$ based on air source heat pump data from the cold climate of northern China (Zhang et al., 2017), replacing fossil fuel boilers with an $80 \%$ efficiency and $100 \%$ efficient electric resistance heating. For hydrogen use, we assume an efficiency based on a gas-fired heat pump (Critoph et al., 2020). Where traditional biomass is replaced, we assume $80 \%$ efficient (for space heating) traditional biomass stoves (Geller, 1982) are replaced with air source heat pumps.

For water heating in buildings, it is assumed that direct use of fossil fuels, electric resistance heating and traditional biomass are entirely replaced by electric heat pumps with an efficiency of $220 \%$, which is the median value of a recent field study (Willem et al., 2017). Where the current fuel is traditional biomass, it is assumed to be used with an efficiency of 14\% (for water heating) based on Geller (1982).

The paper assumes that cooking is completely electrified and that this efficiency is $80 \%$, which is characteristic of a modern electric hob (Hager \& Morawicki, 2013). Traditional biomass displaced is assumed to be used with an efficiency of $6 \%$ for cooking (Geller, 1982).

Lighting, cooling and appliances are already completely electrified. Further efficiency improvements can be expected, but none is assumed here to be the result of the transition.

In transport, it is assumed that electrification occurs in all modes to a greater of lesser extent. The likely penetration of electricity and the emission factors for different vehicle types are taken from a recent comprehensive review (Khalili et al., 2019).

It assumed that light vehicles (cars and vans) are completely electrified. Internal combustion engine vehicles ICE) with a fuel consumption of $0.782 \mathrm{kWh} /$ $\mathrm{km}$ are replaced with battery electric vehicles (BEV) with a fuel consumption of $0.182 \mathrm{kWh} / \mathrm{km}$.

For heavy vehicles it is assumed that only 50\% of total vehicle distance travelled can be electrified, with the remaining 50\% supplied from hydrogen fuel cell electric vehicles (FCEV). Fuel consumption data assumed are for ICE $3.51 \mathrm{kWh} / \mathrm{km}$, for BEV 1.87 $\mathrm{kWh} / \mathrm{km}$, and for FCEV $2.11 \mathrm{kWh} / \mathrm{km}$.

Bus fleets are assumed to be $80 \%$ electrified, with only long distance buses powered by hydrogen fuel cells. Fuel consumption data assumed are for ICE $4.09 \mathrm{kWh} / \mathrm{km}$, for BEV $1.87 \mathrm{kWh} / \mathrm{km}$, and for FCEV $3.12 \mathrm{kWh} / \mathrm{km}$.

Rail transport is currently the most electrified transport mode. We assume that the transition will stimulate a continuation of this trend through to full electrification. Specific energy consumption for rail 
freight engines is $0.04 \mathrm{kWh} / \mathrm{km}$ for electricity compared to $0.1 \mathrm{kWh} / \mathrm{tkm}$ for diesel engines. For passenger railways, the equivalent figures assumed are 0.09 $\mathrm{kWh} / \mathrm{pkm}$ for electric trains and $0.2 \mathrm{kWh} / \mathrm{pkm}$ for diesel.

Aviation is generally assumed to be difficult to electrify, because of the weight of batteries and high power requirements. However, recent work shows that journeys of less than $2000 \mathrm{~km}$ might reasonably be electrified (Schafer et al., 2019). In this paper, we assume electrification of $33 \%$ of total air travel with the remaining $67 \%$ converted to hydrogen. Using data on passenger aircraft, the fuel consumption data assumed are $0.54 \mathrm{kWh} / \mathrm{pkm}$ for conventional planes, $0.2 \mathrm{kWh} / \mathrm{pkm}$ for electric planes and $0.39 \mathrm{kWh} / \mathrm{pkm}$ for hydrogen.

Marine transport remains an important mode for freight. It is widely seen as a difficult mode to electrify with more attention focussing on hydrogen and ammonia as zero carbon options. Here, we assume that electrification is limited to $10 \%$ in short distance trips such as ferries. Using data on marine freight, the fuel consumption assumptions are $0.042 \mathrm{kWh} / \mathrm{tkm}$ for ICEs, $0.019 \mathrm{kWh} / \mathrm{tkm}$ for electric ships and 0.039 $\mathrm{kWh} / \mathrm{tkm}$ for hydrogen-powered ships.

Funding The author acknowledges support for the work undertaken as part of the Centre for Research on Energy Demand (UK Research and Innovation funded Research Grant EP/R035288/1).

\section{Declarations}

Conflict of interest The authors declare no competing interests.

Open Access This article is licensed under a Creative Commons Attribution 4.0 International License, which permits use, sharing, adaptation, distribution and reproduction in any medium or format, as long as you give appropriate credit to the original author(s) and the source, provide a link to the Creative Commons licence, and indicate if changes were made. The images or other third party material in this article are included in the article's Creative Commons licence, unless indicated otherwise in a credit line to the material. If material is not included in the article's Creative Commons licence and your intended use is not permitted by statutory regulation or exceeds the permitted use, you will need to obtain permission directly from the copyright holder. To view a copy of this licence, visit http://creativecommons.org/licenses/by/4.0/.

\section{References}

Arpagaus, C., Bless, F., Uhlmann, M., Schiffmann, J., \& Bertsch, S. S. (2018). High temperature heat pumps: Market overview, state of the art, research status, refrigerants, and application potentials. Energy, 152, 985-1010.

Ayres, R. U., \& Warr, B. (2010). The economic growth engine: how energy and work drive material prosperity. Edward Elgar Publishing.

Brandon, N. P., \& Kurban, Z. (2017). Clean energy and the hydrogen economy. Philosophical Transactions of the Royal Society a: Mathematical, Physical and Engineering Sciences, 375(2098), 20160400

Brockway, P. E., Sorrell, S., Semieniuk, G., Heun, M. \& Court, V. (2021). Energy efficiency and economy-wide rebound effects: A review of the evidence and its implications. Renewable and Sustainable Energy Reviews: 110781

Brown, M. A. \& Wang, Y. (2015) Green savings: How policies and markets drive energy efficiency. ABC-CLIO

CCC (2018a) Climate Change Committee. Hydrogen in a lowcarbon economy. Climate Change Committee

CCC (2018b) Climate Change Committee. Biomass in a lowcarbon economy. UK Climate Change Committee

Critoph, R., Metcalf, S. \& Pacho, A. R. (2020) Gas fired heat pumps as a replacement for condensing boilers. Renewable Energy and Sustainable Buildings 761-770

Cullen, J. M., \& Allwood, J. M. (2010). The efficient use of energy: Tracing the global flow of energy from fuel to service. Energy Policy, 38, 75-81.

Cullen, J. M., Allwood, J. M., \& Borgstein, E. H. (2011). Reducing energy demand: What are the practical limits? Environmental Science \& Technology, 45, 1711-1718.

Deason, J., \& Borgeson, M. (2019). Electrification of buildings: Potential, challenges, and outlook. Current Sustainable/renewable Energy Reports, 6(4), 131-139.

ECUK (2020) Energy consumption in the UK. Table C2. Industrial final energy consumption by subsector, 2018 data https://www.gov.uk/government/statistics/energyconsumption-in-the-uk.

Edenhofer, O. et al (2014) Intergovernmental Panel on Climate Change. Climate change 2014: Mitigation of climate change. 3. Cambridge University Press

Edmonds, J., Wilson, T., Wise, M., \& Weyant, J. (2006). Electrification of the economy and $\mathrm{CO} 2$ emissions mitigation. Environmental Economics and Policy Studies, 7(3), 175-203.

EIA (2014) US Energy Information Administration. 2014 Manufacturing Energy Consumption Survey. https://www. eia.gov/todayinenergy/detail.php?id=16211

Eyre, N. (1997). Barriers to energy efficiency more than just market failure. Energy and Environment, 8, 25-43.

Eyre, N., \& Baruah, P. (2015). Uncertainties in future energy demand in UK residential heating. Energy Policy, 87, 641-653.

Geller, H. S. (1982). Cooking in the Ungra area: Fuel efficiency, energy losses, and opportunities for reducing firewood consumption. Biomass, 2, 83-101.

Georgescu-Roegen, N. (1993) The entropy law and the economic problem 
Gielen, D., Boshell, F., Saygin, D., Bazilian, M. D., Wagner, N., \& Gorini, R. (2019). The role of renewable energy in the global energy transformation. Energy Strategy Reviews, 24, 38-50.

Goldstein, B., et al. (2011). Geothermal energy, in IPCC Special Report on Renewable Energy Sources and Climate Change Mitigation. Cambridge University Press.

Grübler, A., Wilson, C., \& Nemet, G. (2016). Apples, oranges, and consistent comparisons of the temporal dynamics of energy transitions. Energy Research \& Social Science, 22, $18-25$.

Grubler, A., Wilson, C., Bento, N., Boza-Kiss, B., Krey, V., McCollum, D.L., Rao, N.D., Riahi, K., Rogelj J. \& De Stercke, S. (2018) A low energy demand scenario for meeting the $1.5 \mathrm{C}$ target and sustainable development goals without negative emission technologies. Nature Energy. 3(6): 515-527

Hager, T. J., \& Morawicki, R. (2013). Energy consumption during cooking in the residential sector of developed nations: A review. Food Policy, 40, 54-63.

Hammond, G. P., \& Stapleton, A. J. (2001). Exergy analysis of the United Kingdom energy system. Proceedings of the Institution of Mechanical Engineers, Part a: Journal of Power and Energy, 215, 141-162.

Hansen, K., Mathiesen, B. V., \& Skov, I. R. (2019a). Full energy system transition towards $100 \%$ renewable energy in Germany in 2050. Renewable and Sustainable Energy Reviews, 102, 1-13.

Hansen, K., Breyer, C., \& Lund, H. (2019b). Status and perspectives on $100 \%$ renewable energy systems. Energy, 175, 471-480.

He, K., \& Wang, L. (2017). A review of energy use and energy-efficient technologies for the iron and steel industry. Renewable and Sustainable Energy Reviews, 70, $1022-1039$.

IEA (2018a) International Energy Agency. World energy outlook. IE

IEA (2018b) International Energy Agency. The future of petrochemicals. IEA

IEA (2019) International Energy Agency. The future of hydrogen. IEA

IEA (2020a) International Energy Agency. Data and statistics. https://www.iea.org/data-and-statistics?country=WORLD \&fuel=Energy $\% 20$ supply\&indicator=Electricity $\% 20$ gen eration $\% 20$ by $\% 20$ source, accessed $14^{\text {th }}$ August 2020.

IEA (2020b) International Energy Agency. Global electrolysis capacity becoming operational annually, 2014-2023. https://www.iea.org/data-and-statistics/charts/global-elect rolysis-capacity-becoming-operational-annually-20142023-historical-and-announced, accessed 16th August 2020.

IEA (2020c) International Energy Agency. Data and statistics. World energy balance. https://www.iea.org/data-and-stati stics/data-tables?country $=$ WORLD, accessed $16^{\text {th }}$ August 2020

IRENA (2020a) International Renewable Energy Agency. Renewable Power Generation Costs in 2019. IRENA

IRENA (2020b) International Renewable Energy Agency. Hydrogen: A renewable energy perspective. IRENA
Ivanova, D. et al. (2020) Quantifying the potential for climate change mitigation of consumption options. Environmental Research Letters

Jacobson, M. Z., Delucchi, M. A., Bazouin, G., Bauer, Z. A., Heavey, C. C., Fisher, E., Morris, S. B., Piekutowski, D. J., Vencill, T. A., \& Yeskoo, T. W. (2015). 100\% clean and renewable wind, water, and sunlight (WWS) all-sector energy roadmaps for the 50 United States. Energy \& Environmental Science, 8(7), 2093-2117.

Jones, L. E. (2017). Renewable energy integration: Practical management of variability, uncertainty, and flexibility in power grids. Academic Press.

Khalili, S., Rantanen, E., Bogdanov, D. \& Breyer, C. (2019) Global transportation demand development with impacts on the energy demand and greenhouse gas emissions in a climate-constrained world. Energies 12, 3870

Kümmel, R. (2011). The second law of economics: energy, entropy, and the origins of wealth. Springer Science \& Business Media.

Kümmel, R. (2013). Why energy's economic weight is much larger than its cost share. Environmental Innovation and Societal Transitions, 9, 33-37

Laitner, J. A. S. (2015). Linking energy efficiency to economic productivity: Recommendations for improving the robustness of the US economy. Wiley Interdisciplinary Reviews: Energy and Environment, 4(3), 235-252.

Lawrence, A., Thollander, P., Andrei, M. \& Karlsson, M. (2019) Specific Energy Consumption/Use (SEC) in energy management for improving energy efficiency in industry: Meaning, usage and differences. Energies 12, 247

Lazarus, M., Greber, L., Hall, J., Bartels, C., Bernow, S., Hansen, E., Raskin, P. \& Von Hippel D. (1993). Towards a fossil free energy future. The next energy transition. Greenpeace International

Lechtenböhmer, S., Nilsson, L. J., Åhman, M., \& Schneider, C. (2016). Decarbonising the energy intensive basic materials industry through electrification-Implications for future EU electricity demand. Energy, 115, 1623-1631.

Lovins, A. (2013). Reinventing fire: Bold business solutions for the new energy era. Chelsea Green Publishing.

Lucon, O., et al. (2014). Chapter 9: Buildings in Intergovernmental Panel on Climate Change, 5th Assessment Report. Cambridge University Press.

Lund, H., \& Mathiesen, B. V. (2009). Energy system analysis of $100 \%$ renewable energy systems-The case of Denmark in years 2030 and 2050. Energy, 34(5), 524-531.

Lutz, A. E., Larson, R. S., \& Keller, J. O. (2002). Thermodynamic comparison of fuel cells to the Carnot cycle. International Journal of Hydrogen Energy, 27, 1103-1111.

Masson-Delmotte, V. et al. (2018) Global warming of 1.5 C. IPCC Special Report on the impacts of global warming of $1.5 \mathrm{C}$.

McCollum, D., Krey, V., Kolp, P., Nagai, Y., \& Riahi, K. (2014). Transport electrification: A key element for energy system transformation and climate stabilization. Climatic Change, 123(3-4), 651-664.

Moran, M. J., \& Sciubba, E. (1994). Exergy analysis: Principles and practice. Journal of Engineering for Gas Turbines and Power, 116, 285-290.

NGESO (2020) National Grid Electricity System Operator. Future Energy Scenarios 2020. National Grid 
Parra, D., Valverde, L., Pino, F. J., \& Patel, M. K. (2019). A review on the role, cost and value of hydrogen energy systems for deep decarbonisation. Renewable and Sustainable Energy Reviews, 101, 279-294.

Patterson, W. (2014) Electricity vs fire

Philibert, C. (2017). Renewable energy for industry. International Energy Agency.

Sankey, M.H. (1898) Minutes of Proceedings of The Institution of Civil Engineers. Vol. CXXXIV, Session 1897-98. Part IV.

Schäfer, A. W., et al. (2019). Technological, economic and environmental prospects of all-electric aircraft. Nature Energy, 4, 160-166.

Smith, P., et al. (2013). How much land-based greenhouse gas mitigation can be achieved without compromising food security and environmental goals? Global Change Biology, 19, 2285-2302.

Sorrell, S. (2007). The rebound effect: An assessment of the evidence for economy-wide energy savings from improved energy efficiency. UK Energy Research Centre.

Sovacool, B. K. (2016). How long will it take? Conceptualizing the temporal dynamics of energy transitions. Energy Research \& Social Science, 13, 202-215.
Sugiyama, M. (2012). Climate change mitigation and electrification. Energy Policy, 44, 464-468.

Vogl, V., Åhman, M., \& Nilsson, L. J. (2018). Assessment of hydrogen direct reduction for fossil-free steelmaking. Journal of Cleaner Production, 203, 736-745.

Willem, H., Lin, Y., \& Lekov, A. (2017). Review of energy efficiency and system performance of residential heat pump water heaters. Energy and Buildings, 143, 191-201.

Wolfram, P., \& Wiedmann, T. (2017). Electrifying Australian transport: Hybrid life cycle analysis of a transition to electric light-duty vehicles and renewable electricity. Applied Energy, 206, 531-540.

Zhang, Q., Zhang, L., Nie, J., \& Li, Y. (2017). Techno-economic analysis of air source heat pump applied for space heating in northern China. Applied Energy, 207, 533-542.

Publisher's note Springer Nature remains neutral with regard to jurisdictional claims in published maps and institutional affiliations. 